\title{
Ethical issues in child and adolescent psychiatry
}

\author{
Jonathan Green and Anne Stewart

\section{Booth Hall Children's Hospital, Manchester and} Park Hospital, Oxford, respectively

\section{Authors' abstract}

This paper concerns the special ethical problems in child and adolescent psychiatry which relate to the child as a developing being. Two themes are discussed - the sense of responsibility in the child, and the therapist's responsibility towards the child. As a background to understanding the former, ideas on moral and cognitive development are reviewed. The therapist's responsibility is discussed in relation to different styles of therapy and the ethical issues they raise. The article concludes with a number of suggested ethical principles.

\section{Introduction}

Special ethical problems in child and adolescent psychiatry relate to the nature of the child as a developing being, with changing morals, cognitions and emotions, and as a dependent being, reliant on adults - whether parents or professionals. This paper will confine itself to two main themes; namely 1) the child's sense of personal responsibility, initially minimal but developing, and 2) aspects of the therapist's responsibility towards the child.

The theme of responsibility in children raises issues such as their ability to decide for themselves to say no to treatment, or to differentiate between right and wrong at particular ages. The complexity of the substrate for emerging responsibility and the implications that this has for assessment, are matters that this paper will seek to explore. The responsibility of health professionals, on the other hand raises questions about the focus of their responsibility - to the child as an individual, to the family as a whole, to the parents, or sometimes to society. It also raises questions about the particular choice of therapeutic model and the way it is applied and evaluated, as well as the ethical difficulties associated with multiple models of treatment.

\section{Responsibility in the child}

From a developmental viewpoint the emergence of a

Key words

Child psychiatry; adolescent psychiatry; therapy; ethical issues; moral development; cognitive development. quality such as a sense of personal responsibility will $\frac{\Phi}{\omega}$ depend on underlying maturation in cognitive areas $\omega$ and moral reasoning. The relevant concepts in these $\dot{c}$ two fields are summarised below.

\section{COGNITIVE DEVELOPMENT}

The age of seven provides a watershed in logical aspects of cognitive development. In the Middle Ages, it was at seven that the Catholic Church recognised the beginning of the age of reason, and children were first sent to the court as pages and to the guilds as apprentices at the same age. Similarly, in English common law, the age of seven became the threshold of criminal intent. Further, it is around this age in Piaget's description of cognitive development (1) that a child is first able to appreciate and perform logical operations. Before seven, Piaget describes the child's cognition as 'pre-logical' with little adult idea of cause and effect; relationships between objects and events are seen as contiguous; the child, when asked why the sun moved across the sky, might answer 'because it is hot'. Ideas are based primarily on immediate perception and for that reason tend to be intuitive and inconsistent over time. The child's world at this time is fundamentally egocentric. After seven years ideas are still based primarily on concrete external perceptions and objects. However, they can be manipulated in the mind now, according to the logical operations described by Piaget, which allow for the organisation and working through of hierarchies, orders of $\%$ succession, and the combination of different classes $N$ together. There is also an awareness of symmetrical $\underset{\mathrm{W}}{\mathrm{N}}$ relations, so that logical inferences can be worked backward as well as forward.

By the age of nine to ten, adult notions of cause and effect are well established, and the child's egocentricity has begun to give way to an awareness of other people's 0 points of view, and of being involved in a social world. From the age of twelve or so, the grasp of purely abstract ideas becomes firmer, and these can be manipulated according to the more complex operations of propositional logic. This enables the adolescent to identify and begin to produce general laws from individual events, and to be self-reflective in thought.

An important aspect of Piaget's theory is that this last stage of 'formal operations' may only be reached ? 
for any child in certain particularly practised areas, and that in some children the stage of formal operations may not be reached in any area of thinking. Thinking continues to be done with any of the developmental modes previously described and a regression from 'higher modes' may well occur under emotional or physical stress.

Whereas Piaget sees cognitive development as basically biologically determined, although facilitated by social and environmental factors, later cognitive theorists have seen thinking more as a culturally determined activity, and thus with much more plasticity and variability in its development. Bryant (2) sees the child as being potentially logical long before the age of seven years under the right circumstances and Vigotsky and Luria $(3,4)$ see cultural patterns embodied in the adult language surrounding the young child as having an important effect on the formal structure of the developing thought. This notion implies that different cultural conditions can give rise to very different basic thought processes, and this opens the way for important studies of the influence of class, culture and education on cognitive development.

\section{MORAL DEVELOPMENT}

\section{a) Cognitive/developmental theories}

The major influence in this area was Piaget's book, Moral Fudgement of the Child, (5). He suggested that as children mature they pass inevitably through two main stages of moral thought - the stage of moral realism and the stage of moral relativism, with the transition beginning at the age of seven to eight years. Before this age, a child's behaviour is egocentrically determined and based on specific rules; morality is one of constraint rather than co-operation. There is a belief in imminent justice and acts are judged in inflexible terms rather than taking into account motives and intentions. After the age of seven to eight, there emerges a more general conception of right and wrong. There is more co-operative play and the child begins to see that rules are not just dependent on adult enforcement or arbitrary factors but can be based on mutual consent the children themselves can have a part in them. By the age of eleven or twelve years there has been a shift from a moral code which is primarily a response to external demand to a moral code based on internal standards. Kohlberg (6) later developed these ideas. He suggested there were three main stages of moral development: the pre-moral stage where motivation is governed by thoughts of reward and punishment; the morality of conventional rule conformity, where motivation is governed by anxiety about disapproval, and the morality of self-accepted moral principles. Kohlberg, and to some extent Piaget, did take into account social and intellectual influences. These are seen to impede or accelerate rates of development but do not change the essential nature of the stages. It is the maturational process which is emphasised.

\section{b) Psychoanalytic theories}

Freud formulated the idea of the super-ego, developing as a result of weakness of the infantile ego (7). This takes place at the end of the phallic period, age five to six years. The oedipal complex is at its peak, and fear of punishment from parents by the frustrated child, and the need for affection and protection, force the child to accept parental demands and to internalise them. The stronger the feeling of hostility to the parent, the stronger will be the super-ego or conscience. Later analysts came to see the conscience as a more constructive force.

\section{c) Learning theories}

In these theories, moral behaviour is seen as the net result of a pattern of learned behaviours accumulating through childhood. In 1976, Eysenck (8) suggested that individual differences in moral behaviour may be attributed to genetically determined variation in cortical arousal levels, producing variable rates of social conditioning.

A number of researchers have looked at factors affecting moral development, particularly social and family influences. Liu (9) in 1950 compared a group of American children in one district in New York; he found significantly different moral standards which related to different cultural influences. Hardeman (10) looked at the relationship between moral reasoning and conceptual ability. She found a positive correlation between scores on Piagetian conservation tests and scores on a moral reasoning interview schedule, and concluded that conservation ability is a necessary but not sufficient condition for ensuring a mature level of moral reasoning. The relationship between maturity of moral concepts and actual moral behaviour has also been looked at. Grinder (11) found little support for Piaget's idea that as children advance towards mature moral judgement, their behaviour will also change. $\mathrm{He}$ found that the process of maturation that underlies changes in children's understanding of moral concepts is relatively independent of the processes by which they learn to apply concepts of morality to their own behaviour: social pressures from the immediate environment were very important. While moral understanding does not necessarily lead automatically to moral behaviour it is a necessary precondition for it.

\section{RESPONSIBILITY AND DEVELOPMENT}

The Piagetian and other developmentalist theories seem to imply that a child's capacity for responsibility can be precisely determined. In practice the relationship of these developmental processes to moral understanding, and moral behaviour, is not always direct. Moral behaviour may not necessarily reflect moral understanding or even developmental level; other factors or pressures in the immediate situation may be equally important. The developmental theories offer, however, a background to the understanding of 
responsibility. An understanding of oneself as agent of one's behaviour would be unthinkable without the capacity for concrete operations or understanding of cause and effect. The development of non-egocentric thought during the stage of concrete operations would be a pre-condition for early understanding of oneself as part of a social group, and the appearance of formal operations is necessary for an appreciation of ethical principles acting across specific situations. Similarly the change in moral thought from moral realism to moral relativism also seems to be necessary for a development of a sense of responsibility. But added to this must be the vagaries of ego development, and in particular the mechanisms of defence such as denial and projection which can act against accepting responsibility at any stage and may mean that such understanding in crucial areas may take years to come.

Personal accountability and social responsibility in law may be fairly straightforward, but are notoriously slippery when psychological mechanisms for their absence are considered. Clearly the developmental substrate for responsibility is complex and variable, with educational, cultural and social as well as maturational determinants. This produces a level of complexity and uncertainty in the assessment of responsibility in children and there is no method of any rigour for doing this apart from trained intuition.

\section{ADOLESCENT PSYCHIATRY}

Whatever notions of developing responsibility may be desirable for psychological considerations, within adolescent psychiatry particularly doctors have to act within a framework of the law. The following are examples of legal cut-off points:

\section{A child under ten cannot be charged with a criminal offence;}

2. A child aged ten to thirteen can be charged with a criminal offence, but it must be proved that he knew his actions were wrong;

3. A child aged fourteen is assumed in law to be responsible for his acts;

4. A child aged sixteen is able to refuse treatment;

5. A child aged sixteen to eighteen can no longer be put into care unless he consents;

6. A child aged seventeen is subject to the full process of the law;

7. A child aged eighteen can vote.

Psychological development of responsibility is obviously not as clearcut as this, yet we may have to work within this framework. The relationship of authority, for example, between therapist and adolescent will necessarily change throughout the teenage years, especially as the adolescent reaches sixteen when treatment can be legally refused. Information supplied by the Children's Legal Centre (12) indicates that even under this age, if a young person is old enough to understand the nature of treatment and its implications his or her consent is needed in preference to the parents', although ideally there should be both.

A further and related issue is that of confidentiality, which is highlighted by the Gillick case. The Court of Appeal (13) in December 1984 decided that 'the rights and duties of parents are paramount unless overruled by the courts except in emergency'. Thus it was made mandatory for doctors to seek parents' permission in prescribing the contraceptive pill to girls under sixteen, with implications for other forms of treatment too. In October 1985 the House of Lords $(14,15)$ by a close majority ruled that doctors can in certain cases prescribe the contraceptive pill to girls less than sixteen without parental consent. As Lord Scarman said 'parental right yielded to the child's right to make his own decisions when he reached sufficient understanding and intelligence to be capable of making up his own mind'. General Medical Council (GMC) Guidelines make it clear that it is the doctor's duty to make this judgement on a child's maturity and act accordingly (16). This issue is particularly pertinent because adolescents differ so enormously in their emotional, moral and cognitive maturity, making it crucial for the doctor to have a well-trained sense of the development of responsibility. After the age of sixteen neither the doctor nor the parent nor the local authority can override the consent or refusal of adolescents unless they are incapable of expressing their views. In fact only invasive treatment by drugs, ECT etc, are covered in this legal framework (11). Milieu therapy, psychotherapy, behaviour therapy, occupational and family therapy are not, although enforced milieu therapy may be covered by common law on assault. Even though not covered in law children's consent for these latter measures should perhaps be sought, maturity permitting.

The notion of responsibility includes an idea of accountability for behaviour. The difficulty in judging this kind of responsibility is highlighted in the following example:

David is a fifteen-year-old boy with a long history of non-attendance at school, trouble with the law, and being on the fringe of drug-taking. He took an accidental overdose of illicit drugs and was admitted to ITU with respiratory failure. His parents already have one child in care but are trying hard with David to set down limits for him, and have made repeated efforts to get him back to school. David himself claims that the school makes him anxious and unhappy. The drugtaking had given him a sense of security with his peers which had been missing at home and at school. A case conference is held about him. It seems that his parents have been neglectful in their care and are being prosecuted in their failure to get the boy to school. The boy himself says he cannot go to school because he feels so anxious there. How much of his problem is judged to be 'disorder', how much parental failure, how much situational, and how much his responsibility, will greatly colour management decisions in such a case. Perhaps part of management should be to try to 
generate or encourage an increased sense of responsibility in him.

This example highlights the problem of responsibility in practice; a clinician or team is likely to come to an assessment of a child's degree of responsibility through personal contact and discussing his or her behaviour with others. This assessment clearly contains a synthesis of information about many of the layers of stage development and personal circumstance discussed earlier - mixed inevitably with the clinician's own projections and prejudices. Analysis of and reflection on the parameters involved would help to improve this intuition.

\section{The responsibilities of therapists}

In preparing this paper, it soon became apparent how elusive ethical issues often were, and particularly how much easier it seemed to be to see the ethical dimensions and problems in theories and therapies which one does not adhere to as opposed to those one does. Perhaps there is something in the nature of theoretical systems and practice in child psychiatry that is responsible for this 'transparency' of the ethical dimensions in positions adhered to by any particular practitioner. Theory and practice can come to form a closed system of explanation and action applicable over a wide area of behaviour. Most practical situations in child psychiatry allow enough room for manoeuvre for one of a number of possible explanatory systems and resulting treatments to be employed. Thus involved in their theory, therapists will rarely feel at a loss: indeed they may be personally identified with their theoretical position and passionately confident in the resulting action, which seems intuitively right. The uncertainty and conflict is more likely to occur between practitioners of different types of therapy, and of course most types tend to cement their identity by becoming organised and codified and more or less inward-looking. Conflicts of interest or ethical problems which might remain invisible if considered within the bounds of a particular theoretical system, become more obvious when the practice of two systems is contrasted. Although these issues are naturally common to adult as well as child psychiatry, they are perhaps particularly pointed in work with children, due to the dependent and relatively malleable nature of the child.

\section{INDIVIDUAL THERAPY}

Children in long-term individual psychotherapy enter a relationship with an adult of a peculiar intensity which is likely to take on a 'parental quality', at least for the child. According to their theoretical lights, therapists will have different ways of seeing this role and the nature of its benefits. But the way therapists behave is related to the kind of changes they hope to promote in their patients; and although these may seem self-evident to the therapist, it is inescapable that values and attitudes are being transmitted. If the values and attitudes of the child's parents are fundamentally different, the stage is then set for confusion in the child and dilemmas regarding the management. At the extreme these dilemmas can involve professionals acting legally to remove children from their parents' influence (and this legal sanction underlying a therapist's position will naturally make many parents wary from the outset). In a milder form the dilemmas can make progress in therapy most difficult and it is in recognising this that many therapists will only take on children if the parents are in general understanding and in agreement with the implicit attitudes in the therapy. However, this is neither always practicable nor fully practised (and what is one's ethical position towards the children thereby not treated?).

Between professionals the issues here are thrown into even sharper relief by the attitude that a family or systems therapist would have towards the individual problem. Individual therapy would be based on a concept of intrapsychic maturation and the belief that such maturation could take place in the therapy relatively independent of the child's environment. For a family therapist the child's problems would, on the contrary, be seen as symptomatic of a more widelybased disturbance in family relationships. The therapist's behaviour is in accord with this theory: he or she will engage the whole family. Individual treatment then, for many family therapists, can be seen as unacceptably symptomatic: not tackling the 'real' problem. To illustrate the problems that can be posed for individual therapy:

Susan, is a girl in early adolescence in individual psychotherapy. The therapist feels the treatment is going well. This immature, passive, fragmented girl seems to be gaining a sense of herself and becoming happier and more purposeful in her life. Occasionally the parents are seen and on one occasion the father says 'Since our daughter has been in therapy with you she has been drifting away from us, she is no longer interested in talking to us as parents, she seems only to want to go her own way. Our family is breaking up and because of it my wife is threatening to take an overdose. I blame you for this happening!'

The way in which a therapist responds to this challenge from a parent depends on a theoretical or ethical position concerning questions of whether individual growth takes precedence over family integrity, and to what extent individual change is possible without a change in the whole family system. At what age can children, or adolescents take responsibility for their own life to the extent of going a different way from their family, and at what age would it be appropriate to encourage this?

Examples of the way therapists' behaviour is modified by theoretical assumptions could be multiplied indefinitely. Autistic children, for instance, referred to various centres within mainstream child psychiatry can expect very differing treatments. In 
some centres the child would be felt to have an extremely fragile ego with a severe and very early deficit in personality development. The treatment would be predicated on the greatest caution and slowness in initiating contact for fear of overwhelming his fragile defences (17). Other theories, however, see the issues differently, as disturbed conceptual development and socially avoidant behaviour, and one treatment advocated within this theoretical model has been an intrusive approach to break through the avoidance (18). A highly stressful programme of behaviour management and sometimes forced holding despite the child's protestations until there is relaxation, is undertaken. Management styles could not be more different.

\section{FAMILY THERAPY}

Family therapy has grown up over the last two or three decades and seems to avoid some of the ethical problems involved in individual therapy, but brings with it ethical problems of its own. Firstly, there may be a blurring of responsibility. The therapist relates to an 'organism', the family, rather than to individuals and may not see himself as directly responsible for each family member. The identified patient may improve but other children may be affected adversely by the process, or the parent's marriage may suffer. More crucially, the traditional and even statutory duty of child-care professionals to act as advocate of, and in the best interests of, the child can be badly compromised by a systems viewpoint. Some of the recent tragic deaths of children 'at risk' appear from reports to be attributable as much to an exclusively family viewpoint as to neglect or oversight. It is important to be aware of how subtly yet profoundly a therapeutic focus on a family as a unit can alter the perception of an individual child's predicament or needs. Individual therapists have long been aware of how the patient can become 'overvalued' by the therapist (therapeutic commitment, like love, can be blind): the same can clearly happen with families. The danger of treating the family as an 'organism' can so easily be that its health and intactness is gained at the expense of an individual child's. It is a delicate balance which needs a flexible viewpoint.

Can family therapy be harmful? In some sessions, parents may be encouraged to express negative feelings about the child or to each other. Such ventilation may lead to a raised level of expressed emotion generally in the family. Some research indicates that expressed negative emotion in parents when the child is around the age of three is an important predictor of later behaviour disturbance (19). Family therapy can deny the individual his or her rights and autonomy. If a child is not given the opportunity to express throughts or feelings privately, without the rest of the family, family therapy may actually decrease the individual child's responsibilities and whole areas of difficulty may not be discovered. Furthermore the family system may be unbalanced during treatment to an extent which is intolerable or unacceptable to the particular culture of that family and their immediate social environment Finally, in strategic family therapy, issues concerning the therapist's notions of truth come into question The use of paradox may require a kind of dishonesty or the part of the therapist which may be confusing to the family and eventually morally undermining to the therapist.

\section{Discussion}

In the second part of this paper, ethical problems arising out of different theoretical perspectives in childw psychiatry have been emphasised, and it may be fels that there has been an under-emphasis on broad area绐 of agreement which would exist amongst mos: professionals about how to treat children, and also on the increasing basis of scientific data which is availabler today. That there is of course such a broad area of agreement is thrown into focus by considering othermodes of adult/child relationship, and attitude 3 towards children. Lloyd de Mause's historical analysiš of these different modes (20) is a useful clarification? even though the historical sequence and theoreticalo underpinnng might be debatable (Table 1). Therapists from varying persuasions would find common ground in general attitudes towards children, which woulde probably fall within the 'socialising', 'helping', an perhaps 'intrusive' modes. They would also be in agreement in seeing other modes as pathological and families practising them as in need of help. Although few families in reality would practise any of these modes in pure form the socialising and helping modeswould probably represent the ideal today. Elements of other modes can be seen in society today and form an important part of child psychiatric practice.

The theme of the first part of this paper was the emerging sense of responsibility in the child, dependent as that is on mental maturation, and how this affects the way clinicians act. This theme clearly arises out of typical concerns of the socialising ando helping modes: the identification of the particular nature and special needs of the child of differing ages, and the adult concern to adapt to these and facilitate maturational processes. However, despite this measure of agreement, which might be expected across 0 a wide spectrum of approaches within child psychiatry important differences do exist. Although differento theoretical perspectives may address themselves too different levels of reality and thus not necessarily be mutually exclusive, they can in practice have very? different practical consequences for action, which doo raise ethical issues. How then are clinicians in child $\overrightarrow{\mathrm{P}}$ psychiatry to develop ethical ground-rules to cope with the profusion of frameworks of understanding and treatment which are each largely closed and self confirming? Would it for instance be possible or even desirable completely to open up these theories too testing? Their strength and indeed therapeutic effect may to some extent depend on their closedness. Ir terms of therapy, there is clearly a dialectic here 
between the need for the therapist to hold strong, consistent (and hence somewhat closed) therapeutic ideas, and the need for both therapist and theory to be open to change and reality confrontation. In our view this dialectic is inevitable in that it reflects the dynamics of a healthy ego. A saying attributed to Gandhi illustrates this paradox: 'I wish all the doors of my home to be open to the winds of different opinion, but not to let them blow me off my feet'.

One of the prime experiences in psychotherapy is the patient's contact with such a 'healthy' ego, and the therapist will, in the therapy, create such an ego out of his or her own capacities as a person supplemented and enriched by theory as necessary (a particular kind of ego, this 'therapeutic ego' certainly, but one that a patient can increasingly trust in and work with). The theory then, as well as the person of the therapist, will need to have this quality of clear identity combined with openness.

There is little likelihood that explanatory systems in psychiatry will ever be wholely scientifically testable in a Popperian sense; they could only do this by ignoring such huge areas of reality as to be impossibly limited in a clinical setting (this is not to say that the specificity and the efficacy of the explanatory models should not be rigorously investigated). The suggested ethical principles of therapists' responsibility which follow, therefore, assume a background of diversity in both theory and practice which exists now and which is likely to remain.
1. Therapists have a responsibility to discuss the range of possible treatment options and from this agree a 'contract' for treatment.

Such issues as the merits of individual versus family therapy, length of treatment, and what might be expected of participants could be discussed, along with a realistic appraisal of the likely outcome.

2. There may be limitations to therapy with a family who hold very different assumptions from the therapist about child rearing, and which they do not wish to change.

There is obviously an important boundary here at which a particular family's assumptions may be so socially deviant that the law must come into force. However, this is a different matter from the purely therapeutic issues.

3. There needs to be a balance between the therapeutic strength of a relatively closed system of theory, and the need to be open to reality testing by means of discussion between systems and, crucially, by audit of treatment outcome.

The same would apply within an individual treatment: the need for a consistent approach being balanced against a constant appraisal of its effectiveness, and new needs emerging in the client.

4. In training, the personal development of the therapist should be as important as the development of his or her theory.

Therapists have a personal responsibility to develop insight into their motivation and attitudes in relation to their work and choice of theoretical position, for it would be wrong if such a position was merely an

\section{TABLE 1}

\section{Modes of parent/child interaction seen historically (Lloyd de Mause 1974)}

\section{INFANTICIDE MODE Antiquity - C4th AD}

Parental anxieties typically resolved by killing the child.

ABANDONMENT MODE C4 - 13th

Parents escape from the dangers of their own projections by abandoning the child.

\section{AMBIVALENT MODE C14-17th}

Child a container for projections, but can be 'moulded into shape'.

\section{INTRUSIVE MODE C18th}

Parents feel safe to come closer to their children with empathy. Wish to understand their minds, control their will. Birth of paediatrics.

\section{SOCIALISATION MODE C19 - mid-20th}

Emphasis on training rather than conquering. Growth by Guidance. Includes Freud's and Skinner's theories.

\section{HELPING MODE C Mid-20th}

Parents serve child, facilitate internal development by supplying all need. No external discipline or habit formation. 
elaboration of their own defences or internal conflicts. 5. The ethics of much of the therapeutic work in child psychiatry is situational and personal and should be recognised as such.

Formal training in some form of analytic ethics would be very appropriate in preparation for work in this field.

6. Therapists need to evaluate carefully the emerging sense of responsibility in the child and how this interacts with their responsibility as therapists and the responsibilities of parents, adapting their therapeutic stance accordingly.

\section{Acknowledgements}

This paper arose out of a series of seminars on ethical issues in psychiatry, held at the Department of Psychiatry in Oxford. We are grateful to Dr Sidney Bloch for encouraging us to present this topic, and to Dr William Parry-Jones for his very helpful comments in the early stages of preparation.

Fonathan Green MA (Cantab) MB BS MRCPsych DCH is Senior Registrar, Department of Child Psychiatry Booth Hall Children's Hospital, Manchester. Anne Stewart BSc MB BS MRCPsych DCH is Senior Registrar, Park Hospital, Oxford.

\section{References}

(1) Piaget J, Inhelder B. The growth of logical thinking from childhood to adolescence. London: Routledge and Kegan Paul, 1958.

(2) Bryant P. Perception and understanding in young children. London: Methuen, 1974.

(3) Vigotsky L S. Thought and language. Cambridge, Mass: MIT Press, 1962.

(4) Luria A R. Towards the problem of the historical nature of psychological processes. International journal of psychology 1971; 6: 259-272.
(5) Piaget J. Moral judgement of the child. London Routledge and Kegan Paul, 1932.

(6) Kohlberg L. The development of children's orientation toward the moral order. Sequence in the development of human thought. Vita Humana 1963; 6: 11-33.

(7) Freud S. On narcissism - an introduction. Vol 14 Collected Works. London: Hogarth Press, 1914.

(8) Eysenck H J. The biology of morality In: Lickona T, ed. $\stackrel{\bar{\top}}{\widehat{T}}$ Moral development and behaviour. New York: Holt Rinehart and Winston, 1976.

(9) Liu W. Influence of cultural background on moral judgement in the child. Unpublished $\mathrm{PhD}$ thesis, quoted in Jersild A. Child psychology. London: Staplers Press $\overrightarrow{2}$ 1968.

(10) Hardeman A M. Relationship between moral reasoning and conceptual ability. Dissertation abstracts 1967;67 285-B 216.

(11) Grinder R E. Relationship between behaviour and $\vec{\omega}$ cognitive dimensions of conscience in middle childhood $\overrightarrow{i r}$ Child Development 1964; 35: 881-891.

(12) Children's Legal Centre. The issue of consent to treatment. Information sheet, 1982. See also: Children's Lega Centre. Landmark decision for children's rights. Information sheet, 1986.

(13) Anonymous. Teenage confidence and consent [editorial]. British medical journal 1985; 290: 144-145.

(14) (1985) 3 All ER 385-448: 413.

(15) Dyer C. Contraception and the under 16's: House of Lords ruling. British medical journal 1985; 291: 12081209.

(16) Anonymous. Professional confidence: doctors advised $\overline{\bar{O}}$ to assess child's maturity [editorial]. British medicat̆ journal 1986; 292: 570.

(17) Bettleheim B. The empty fortress. New York: The Free Press, 1967.

(18) Clancy H, McBride G. The autistic process and its treatment. Fournal of child psychology and psychiatry 1969; 10: 233-244.

(19) Thomas A, Chess S. Genesis and evolution of behavioural disorders: from infancy to early adult life. American journal of psychiatry 1984; 141: 1-9.

(20) De Mause L. History of childhood. London: Methuen, 1974. 